\section{Tratamento alternativo de feridas de papilas mamárias de vacas através do emprego de membrana biológica (Biofill)*}

\author{
Alternative treatment in tits wounds in cows by using biological \\ membrane (Biofill)
} José Antonio MARQUES '; Julieta Rodini Engracia de MORAES ';
Francisco José TEIXEIRA NETO'
CORRESPONDENCE TO: José Antonio Marques Hospital Veterinário Faculdade de Cièncias Agrárias e Veterinárias da UNESP Rodovia Carlos Tonanni, $\mathrm{Km} 5$ Campus Jaboticabal 14870-000 - Jaboticabal - SP - Brasil e-mail: fcavj@jab000.uesp.ansp.br

1- Faculdade de Ciências Agrarias e Veterinárias da UNESP - Jaboticabal, SP.

\title{
RESUMO
}

\begin{abstract}
Neste trabalho, avaliou-se a evolução cicatricial de feridas provocadas experimentalmente em papilas mamárias de 16 vacas não lactentes, através do emprego de uma membrana biológica que substitui temporariamente a pele, comparando-a com tratamento à base de pomada epitelizante. Em cada animal, a membrana foi colocada na ferida da papila mamária anterior direita e o tratamento com pomada foi realizado na papila mamária posterior direita. Foram feitas observações clínicas e análise histológica no $3^{\circ}, 7^{\circ}, 14^{\circ}$ e $28^{\circ}$ dias do pós-operatório. Das observações realizadas, verificou-se que as papilas tratadas com a membrana biológica cicatrizaram com uma semana de antecedência, quando comparadas às controle (pomada epitelizante). A utilização da membrana biológica permitiu ainda uma redução na freqüencia de curativos.
\end{abstract}

UNITERMOS: Cicatrização; Vacas; Tetos.

\section{INTRODUCÃO}

$\mathrm{F}$ eridas ou lacerações da teta são lesões que não chegam a penetrar no canal galactóforo. Estas feridas apresentam lormas variáveis com tecidos lacerados ou necrosados. Segundo Grunert ${ }^{2}$ (1958) e Teuscher ${ }^{4}$ (1975), as más condições de manejo e o aumento de volume da mama no período perinatal são fatores predisponentes à ocorrência destas lesões. Turner; Mclwraith" (1985) constataram que as lacerações não penetrantes à mucosa da teta têm rápida cicatrização e recomendaram o tratamento tópico com antissépticos e pomaclas epitelizantes.

A presente pesquisa objelivou avaliar um método alternativo para tratamento de feridas de papilas mamárias de vacas, através do emprego de película de celulose (BIOFILL**), observando-se o período de recuperação e a evolução macro e microscópica das lesões, uma vez que, no homem, curativos de lesões como queimaduras, zonas doadoras e receptoras de enxertos de pele, dermoabrasões, entre outras, são tratadas com sucesso com a membrana de celulose.

\section{REVISÃO DE LITERATURA}

O efeito cicatrizante da película de celulose vem sendo

\footnotetext{
* Projeto linanciado pelo Conselho Nacional de Desenvolvimento

Cientílicos e Teconológico (Proc. 301970/88-2)
}

** BIOFILL Produtos Biotecnológicos - Curitiba, PR pesquisado em medicina humana. Rebelo et al. ${ }^{7}$ (1987) realizaram um estudo relativo à sua utilização em cirurgia reparadora. Os melhores resultados na redução do período de cicatrização foram obtidos em queimaduras de segundo grau. com tempo médio de cicatrização de 12 dias ( \pm ( $) 2$ dias). Em zonas doadoras de pele de espessura parcial, a média de cicatrização foi de 11 dias ( $\pm(12$ dias). Em dermoabrasão, obteve-se média de cicatrização de 8 dias ( \pm 02 dias). Os autores relataram ainda que a película apresentava boa aderência ao leito cruento da ferida, com consequiente alívio da dor, diminuição da contaminação, hemostasia e abreviação do tempo de cicatrização.

Cabral e' al.' (1987) obliveram bons resultados com o emprego da película de celulose no tratamento de queimaduras no homem. Os pacientes apresentaram reepitelização da área afetada em torno do 25" dia de observação. Concluíram ainda, que a aplicação da membrana sobre a área desepitelizada torna a sensação de dor praticamente ausente, impede a contaminação bacteriana secundária, diminui as perdas protéicas e eletrolíticas e reduz o período de hospitalização do paciente.

De Paola; Souza² (1987) estudaram a possibilidade da utilização da película de celulose após a exérese de tumorações infectadas, quando não existiam condições para a reconstituição plástica definitiva. Observaram que seu custo é baixo, dispensando a troca de curativos e o uso de antibióticos.

Peixoto; Santos (1988) avaliaram a utilização da película de celulose em cinquienta e dois pacientes com queimaduras de segundo grau, dermoabrasão e área doadora de enxerto. Constataram que o tempo médio de cicatrização foi de 13, 11 
e 15 dias, respectivamente.

Pitanguy et al. (1988) utilizaram a película em dermoabrasão de segundo grau e áreas doadoras de enxerto, num tolal de 113 pacientes. Concluíram que, em áreas nas quais não se exigiu grande elasticidade da película, a mesma demonstrou ser altamente eficaz.

Hilário; Vasquez (1988) relataram o emprego da película de celulose na cobertura provisória de lesões cutâneas. Foram tratados 48 pacientes portadores de lesões cutâneas com várias etiologias como queimaduras de segundo e terceiro graus, áreas doadoras de enxerto de pele, úlceras crônicas, entre outras. Nestas, o tempo médio de epitelização foi de 15 dias.

Em Medicina Veterinária, Wouk; Michelotto Junior ${ }^{10}$ (1989) estudaram o uso da película de celulose no tratamento de uma ferida de grande extensão em um eqüino. Após 15 dias de tratamento convencional efetuou-se a aplicação da película, sendo que, após 45 dias, o animal reiniciou suas atividades e, no 104" dia de observação, a cicatrização chegou a termo.

\section{MATERIAL E MÉTODO}

\section{Animais}

Foram utilizadas 16 vacas mestiças, com idade entre 4 e 8 anos, fora do período de lactação, provenientes do Município de Jaboticabal-SP. Os animais foram previamente selecionados e examinados, excluindo-se os que apresentavam alterações morfo-fisiológicas das papilas mamárias.

\section{Procedimento cirúrgico}

As vacas foram contidas em tronco apropriado na posição quadrupedal. Após procedimento rotineiro de assepsia e antissepsia das papilas mamárias, foi realizada anestesia local infiltrativa na base das tetas do lado direito com solução de cloridrato de lidocaína a $2 \% * * *$. Em seguida, procedeu-se a exérese da pele e tecido celular subcutâneo com o auxílio de bisturi e tesoura cirúrgica. As feridas, de forma retangular, mediam 2,0 x 2,5 cm.

A ferida da papila mamária anterior direita de cada animal recebeu aplicação do Biofill e a papila posterior direita tratamento com pomada epitelizante****.

Conduta pós-cirúrgica e aplicação da membrana de celulose

A aplicação da membrana de celulose foi feita obedecendo ao seguinte protocolo:

- Desinfecção das feridas com iodo polivinil pirrolidona $* * * * *$.

-Recorte da película no formato da ferida, obtendo sobras de $0.5 \mathrm{~cm}$ nas bordas.

-Aplicação da película ou pomada epitelizante sobre o leito receptor.

\footnotetext{
**** Xylocitina 2\% - Merrell Lepetil

***** Ganadol pomadia - Laboratório Wyeth Lida.

***** Povidine Tópico - Liboratório Ceras Johnson
}

- Ajuste da película sobre a ferida com o auxílio de gaze estéril embebida em solução fisiológica, retirando-se ao mesmo tempo as bolhas de ar existentes por meio de compressão digital.

-Após a perfeita coaptação da película ao leito receptor, retornou-se o animal ao piquete.

\section{Acompanhamento da evolução cicatricial}

Para acompanhamento da evolução cicatricial, as feridas das papilas mamárias foram medidas no sentido transversal e longitudinal com instrumento de precisão (paquímetro). Efetuaram-se também biópsias, com auxílio de "punch" de $0,5 \mathrm{~cm}$ de diâmetro. As colheitas de fragmentos para histologia obedeceram ao seguinte cronograma: 3 (três), 07 (scte), I4 (quatorze), 21 (vinte e um) e 28 (vinte e oito) dias após o início do experimento.

Os fragmentos teciduais foram fixados em formalina a $10 \%$ por 24 horas e processados segundo as técnicas usuais em histologia. Os cortes histológicos de 7 micrômetros loram corados pela Hematoxilina-Eosina e examinados em microscopia óptica.

\section{RESULTADOS}

As feridas tratadas com pomada epitelizante apresentaram crostas e tecido de granulação aparentemente mais exuberantes. A cicatrização chegou a termo a partir do $35^{\circ}$ dia.

A observação clínica das feridas tratadas com a película de celulose revelou perfeita tolerância dos animais frente à terapia. Verificou-se que a partir do $14^{\circ}$ dia ocorreu maior velocidade de retração das feridas tratadas com a película de celulose. Com este tempo de evolução houve, em média, uma retração de $0,5 \mathrm{~cm}$ no comprimento e $0,8 \mathrm{~cm}$ na largura, enquanto que as feridas tratadas com pomada apresentaram neste mesmo período uma redução de 0,2 e $0.3 \mathrm{~cm}$ nos sentidos longitudinal e transversal, respectivamente (Fig.l). No $28^{\circ}$ dia de evolução, as feridas tratadas com a película de celulose apresentaram-se completamente cicatrizadas, chegando a termo em média 7 dias antes das tratadas de forma convencional (Fig. 2).

A avaliação microscópica das biópsias efetuadas no 3" dia de evolução das feridas revelou ausência de epitélio, reação inflamatória acentuada, caracterizada por edema generalizado da epiderme e infiltrado celular constituído predominantemente por polimorfonucleares neutrófilos. O tecido conjuntivo denso mostrou áreas dilaceradas e desorganização no arranjo dos feixes colagenosos.

Nas feridas recobertas pela película de celulose a reação inflamatória, apesar de presente, mostrou-se menos intensa em função do menor número de células inflamatórias, edema mais discreto e maior organização dos feixes colatgenosos.

No $7^{\prime \prime}$ dia ambas as feridas apresentaram-se sem o revestimento epitelial. Nas feridas controle, a reação inflamatóriat mostrou-se mais intensa, com grande número de polimorfonucleares distribuídos pela derme. Essas células infilltravam- 


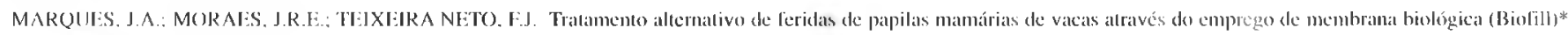

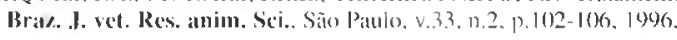

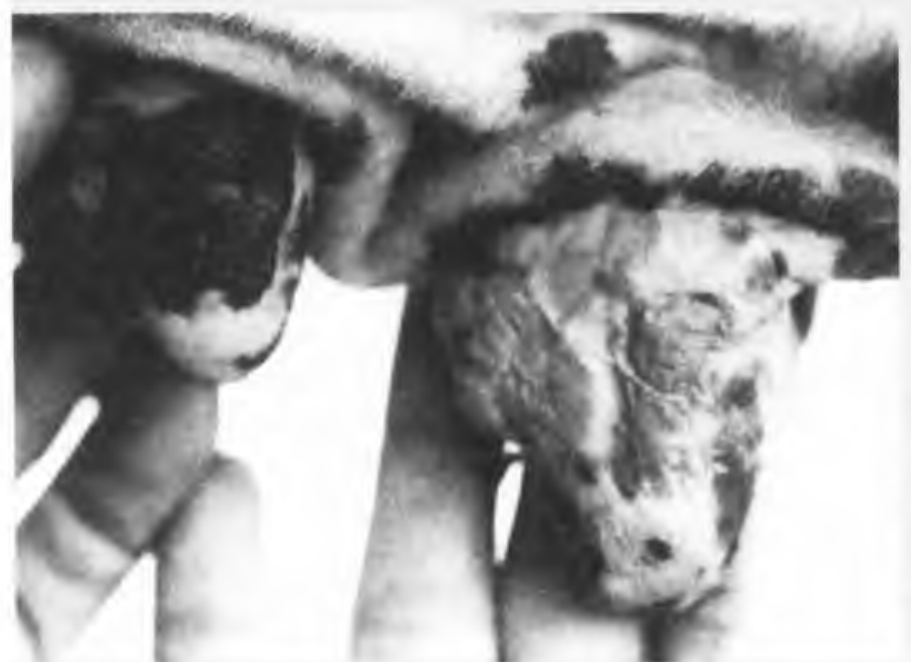

FIGURA 1

Papilas mamárias no $14^{\circ}$ dia do pós-operatório: presença de crostas na papila do grupo controle e na tratada com Biofill maior retração cicatricial.

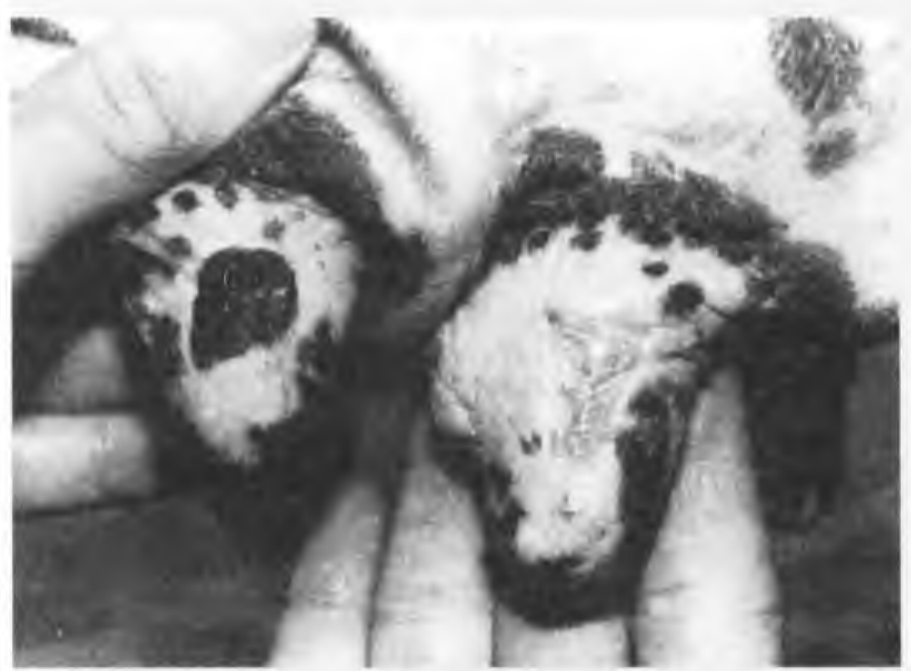

\section{FIGURA 2}

Papilas mamárias no $28^{\circ}$ dia do pós-operatório; na ferida controle, presença de crostas e completa cicatrização na tratada com Biofill.

se pelo tecido conjuntivo denso modelado que se apresentou ainda desorganizado, com disposição aleatória dos feixes colagenosos. Vasos congestos e dilatados foram observados nas feridas traladas com pomada e nas recobertas com a película de celulose. Entretanto, nestas últimas, houve predo-

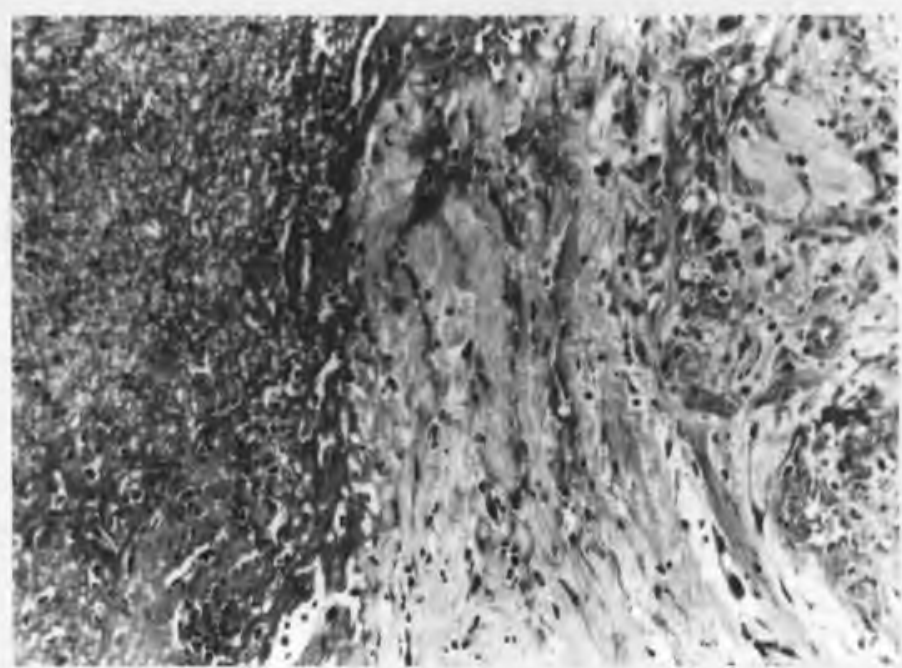

FIGURA 3

Corte histológico da ferida controle no $14^{2}$ dia. Observase reação inflamatória aguda e difusa, derrame plasmático e edema inflamatório. Coloração HE, 36X.

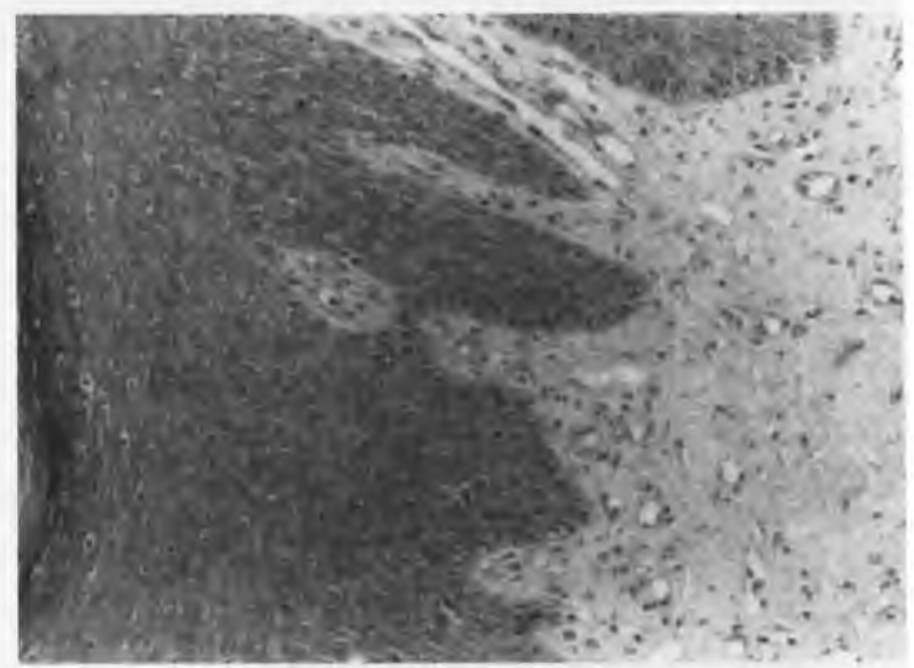

FIGURA 4

Corte histológico da ferida recoberta no $28^{2}$ dia. Observase epitélio totalmente reconstituido, revestido por queratina. $O$ tecido conjuntivo denso apresenta-se remodelado com grande quantidade de colágeno. Vasos neoformados ainda presentes, Coloração HE, 36X.

mínio de macrófagos entre as células inflamatórias e grande número de vasos neoformados. Além disso, a superfície da lerida, apesar de desprovida de epitélio, mostrou-se mais contínua, indicando uma certat remodelação das estruturas externas. 
MARQIJES. J.A; MORAES, J.R.E.; TEIXEIRA NETO. F.J. Tratamento alternativo de feridas de papilas mamárian de vacas alravés do emprego de membrana hiológica (Biolill)* Braz. J. vet. Res. anim. Sci.. Sä̀ Paulo, v.33, n.2. p.102-106. 1996.

No 14" dia as diferenças começaram a ficar mais eviden1es. As feridas recobertas com a membrana biológica mostraram-se ainda sem epitélio, com reação inflamatória discreta. O tecido conjuntivo denso apresentava-se ainda desorganizado e com cório edemaciado. As feridas tratadas de forma convencional apresentaram reação inflamatória com característica mais aguda e difusa, infiltrando-se pela derme. Verificou-se lambém derrame plasmático, congestão vascular e edema pronunciado, caracterizando um quadro inflamatório mais agudo (Fig. 3).

No $21^{\circ}$ dia as feridas submetidas a ambos os tratamentos tinham resquícios de reação inflamatória, com predomínio de macrólagos e congestão vascular. As feridas recobertas com membrana biológica mostraram epitélio de revestimento reconstituído com células epiteliais pavimentosas biestratificadas, que estavam recoberlas por camadas lilamentares de queratina. O tecido conjuntivo denso modelado apresentou-se bem organizado, com disposição paralela e ordenada de feixes de colágeno que preenchiam totalmente a derme. Evidenciaram-se fibras musculares lisas e poucos vasos neoformados. Nas feridas controle observou-se um início de formação de epitélio com células de revestimento dispostas sequiencialmente e sobrepostas, entretanto sem caracterizar estratificação.

No 28 "dia observou-se, nas feridas tratadas com a membrana biológica, revestimento total do epitélio queratinizado. O tecido conjuntivo denso apresentou-se totalmente remodelado com maior quantidade de colágeno. Vasos neoformados ainda foram observados independentemente do tratamento utilizado (Fig. 4).

\section{DISCUSSĀO}

Os resultados do presente trabalho mostraram que, em feridas de papilas mamárias de bovinos, a película de celulose possibilitou uma redução no tempo de cicatrização. As feridas tratadas com a membrana biológica cicatrizaram, em média, com 7 dias de antecedência quando comparadas às feridas controle (pomada epitelizante). Os trabalhos desenvolvidos por Hilário; Vasquez (1988); Peixoto; Santos (1988) e Pitanguy e't al." (1988) corroboram com os resultados oblidos, uma vez que estes lambém reportam uma redução no período de cicatrização de lesões cutâneas tratadas com o Biolill no homem.

No que se refere a curativos, observou-se que não houve necessidade de cuidados diários nas feridas tratadas com a película de celulose. Wouk: Michelotto Junior"(1) (1989) também verificallam que, em feridas de equiinos, a membrana biológica possibilitou uma menor frequiência de curativos, reduzindo o "stress" calusaldo pela contenção diária do animal.

Neste trabalho, verificou-se que a membrana biológica é de fácil aplicação e manuseio e apresenta durabilidade e boa aderência ao leito cruento. Estas vantagens foram descritas por Peixoto; Santos (1988), que avaliaram o Biofill em lesões cutâneals no homem.
Não foi objeto deste estudo verificar os custos financeiros do tratamento, contudo constatou-se que curativos diários são dispensáveis quando do emprego da película de celulose. Pitanguy et al." (1988) afirmaram que o curativo biológico (Biofill), quando comparado com os tratamentos convencionais no homem, é mais econômico, uma vez que há diminuição no número de curativos, bem como no tempo de hospitalização do paciente.

Por não ter sido utilizada em locais que apresentavam mobilidade, pode-se afirmar que, nas condições deste trabalho, a película adaptou-se adequadamente ao leito cruento. Ao contrário, Peixoto; Santos (1988) reportaram observações a respeito da falta de elasticidade da película, quando empregada em áreas com movimentos e tensão, impedindo sua aderência e permanência no leito receptor.

O uso da película de celulose em lesões culâneas no homem, segundo Hilário; Vasquez (1988), impede a instalação de processos infecciosos. Nas condições deste trabalho não foi permitido fazer tal afirmação, mas os dados de observação clínica não evidenciaram a presença de contaminação, podendo ser objeto de futuras pesquisas, a presença ou não de agentes contaminantes. No entanto, Wouk; Michelotto Junior $^{\prime \prime}$ (1989), verificaram que, quando a ferida está contaminada, esta pode ser tratada através de uma pequena abertura na película, através da qual as secreções são drenadas, permitindo também a introdução de medicamentos.

Quando se compara o tempo de cicatrização nas feridas tratadas com o Biofill e o controle, observa-se que, nas feridas onde foi utilizada a membrana biológica, ocorreu cicatrização em menor espaço de tempo, fato este comprovado pela análise histológica dos ferimentos. Por meio desta. podese aferir que a película de celulose possivelmente promova uma diminuição da fase inflamatória do ferimento, possibilitando cicatrização mais rápida por facilitar a regeneração dos tecidos afetados. Além disso, a película parece oferecer um suporte morfo-estrutural, facilitando a remodelação mais adequada do tecido conjuntivo.

Neste estudo pôde-se observar a comodidade do tratamento com a membrana biológica, pois os resultados oblidos com o uso da película em feridas cruentas de papilas mamárias são bastante alentadores, visto que não há necessidade de curativos diários, facilitando o trabalho do médico veterinário militante nos rebanhos leiteiros.

\section{CONCLUSÃO}

A membrana biológical apresenta-se como um curativo eficaz para lesões de papilas mamárias de vacas. Por ser transparente, permite uma constante inspeção da ferida, com diminuição na frequiência de curativos.

O curativo biológico acelera a cicatrização pela diminuição da fase inllamatória aguda, estimulando, de alguma maneira, a remodelação da lerida com a reposição mais rápida do epitélio e organização do tecido conjuntivo denso modelado, caracterizando uma ferida com perdas menos evidentes da estrutura morfofuncional. 


\section{SUMMARY}

This work evaluated the healing of experimentally provoked wounds in the tits of 16 nonlactant cows, by using a biological membrane that temporarily substitutes the skin, and by comparing it with the treatment with ointment. In each cow, the membrane was placed over the wound in the front tit of the right side, and the treatment with ointment was done in the hind tit of the right side, too. Clinical observations and histological analyses were performed on the $3 \mathrm{rd}$, 7 th, 14th and 28th days after the inflicting of the wound. From the observations it was possible to verify that tits treated with the biological membrane healed one week before those in the ointment-treated group. Furthermore the utilization of the biological membrane enables less frequent dressings.

UNITERMS: Healing; Cows; Teats.

\section{REFERÊNCIAS BIBLIOGRÁFICAS}

1-(АВRАI. L..M.: (IAT'TA\%. M.I).: FACTORE, L.A.P.; MATTAR, J.A.; DIAMENT. D.: DE OI.IVEIRA. A.M. Curativo biológico no tratamento do grande queimado: apresentação de caso. Revista Brasileira de Cirurgia. v.77, n.6. p.383-9, 1987.

2-De PAOLA, D.A.; SOUZA, M.G.P.P. Película celulósica. novo curativo biológico para melhoria do leito receptor de enxertia cutânea. Revista Brasileira de Cirurgia. v.77. n.3, p.375-8, 1987.

3-GRUNERT. E. Zur Behandlung der Zitzenschalmunden bein Rind un ter besonderer Berüuchsichtigung der Hauttransplantation. Deutsche Tierärztliche Wochenschrift. v.11 . p.28.5-9. 1958

4-HIL ÁRIO. H.A.; VASQUEZ. L.A.M. Uiilização de um substituto temporário da pele nas perdas cutâneas de pacientes ambulatoriais. Revista Brasileira de Cirurgia. v.78. p. 393. 1988

5-PEIXOTO. R.; SANTOS, D.N. Biofill: uso e avaliação clínica de uma película celulósica em lesōes cutâncas. Revista Brasileira de Cirurgia. v.78, n.2, p.141-5, 1988.

6-PITANGUY, I.; SALGADO, F.; MARACAJÁ, P.F. Utilização de película de celulose (Biofill) como curativo biológico. Revista Brasileira de Cirurgia, v.78, n.5, p.317-26, 1988.

7-REBELL.O, C.; ALMEIDA, D.A.; LIMA JUNIOR, E.M. Biofill, um novo subslituto de pele: nossa experiência. Revista Brasileira de Cirurgia. v.77, n.6, p.407-14, 1987.

8-TEUSCHER, R. Enfermidades de los organos genitales femininos. In: BOLS, W.; DIETZ, O.; SHLEIFER, H.; TEUCHER, R. Tratado de patologia cirúrgica especial para veterinários. 2.ed. Zaragoza, Acribia, 1975. v.1, p.499-524.

9-TURNER, A.S.; Mcll.WRAITH, C.W. Téenicas cirúrgicas em animais de grande porte. São Paulo, Rocca, 1985. p.318-21.

I0-WOUK, A.F.P.F; MICHEI O'TTO JUNIOR, P.V. Relato preliminar do uso de um novo curativo biológico (Biofill) em feridas de pele com grande perda de substância em um eqüino. A Hora Veterinária, v.8, n.47. p. 31-4, 1989 . 